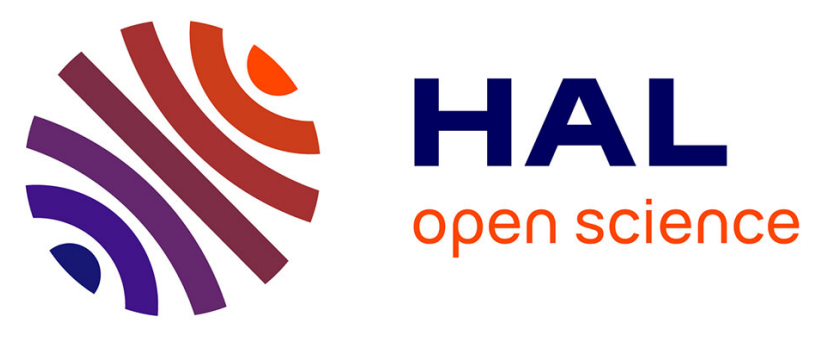

\title{
Hilar fat infiltration: A new prognostic factor in metastatic clear cell renal cell carcinoma with first-line sunitinib treatment
}

Solene-Florence Kammerer-Jacquet, Angélique Brunot, Karim Bensalah, Boris

Campillo-Gimenez, Mathilde Lefort, Sahar Bayat, Alain Ravaud, Frantz

Dupuis, Mokrane Yacoub, Gregory Verhoest, et al.

\section{To cite this version:}

Solene-Florence Kammerer-Jacquet, Angélique Brunot, Karim Bensalah, Boris Campillo-Gimenez, Mathilde Lefort, et al.. Hilar fat infiltration: A new prognostic factor in metastatic clear cell renal cell carcinoma with first-line sunitinib treatment. Urologic Oncology: Seminars and Original Investigations, 2017, 35 (10), pp.603.e7 - 603.e14. 10.1016/j.urolonc.2017.05.015 . hal-01632553

\section{HAL Id: hal-01632553}

\section{https://hal-univ-rennes1.archives-ouvertes.fr/hal-01632553}

Submitted on 10 Nov 2017

HAL is a multi-disciplinary open access archive for the deposit and dissemination of scientific research documents, whether they are published or not. The documents may come from teaching and research institutions in France or abroad, or from public or private research centers.
L'archive ouverte pluridisciplinaire HAL, est destinée au dépôt et à la diffusion de documents scientifiques de niveau recherche, publiés ou non, émanant des établissements d'enseignement et de recherche français ou étrangers, des laboratoires publics ou privés. 


\section{Hilar fat infiltration: a new prognostic factor in metastatic clear cell renal cell carcinoma with first-line sunitinib treatment}

Running title: Hilar fat infiltration in metastatic renal carcinoma

Solène-Florence Kammerer-Jacquet ${ }^{1,2^{*}}$, Angelique Brunot $^{3^{*}}$, Karim Bensalah ${ }^{4}$, Boris Campillo-Gimenez ${ }^{5}$, Mathilde Lefort ${ }^{6}$, Sahar Bayat ${ }^{6}$, Alain Ravaud ${ }^{7}$, Frantz Dupuis ${ }^{8}$, Mokrane Yacoub $^{8}$, Gregory Verhoest ${ }^{4}$, Benoit Peyronnet ${ }^{4}$, Romain Mathieu ${ }^{4}$, Alexandra Lespagnol $^{9}$, Jean Mosser ${ }^{9}$, Julien Edeline ${ }^{3}$, Brigitte Laguerre ${ }^{3}$, Jean-Christophe Bernhard ${ }^{10}$ et Nathalie Rioux-Leclercq ${ }^{1,2}$

*These authors contributed equally to the work and are considered as co-first authors

Affiliations:

1- Université de Rennes 1, Université Bretagne Loire, Service d'Anatomie et Cytologie Pathologiques, F-35042 Rennes, France

2- UMR 6290-IGDR, Rennes, France

3- Service d'Oncologie Médicale, Centre Eugène Marquis, Rennes, France

4- Université de Rennes 1, Université Bretagne Loire, Service d'Urologie, F-35042 Rennes, France

5- Service de Statistiques Médicales, Centre Eugène Marquis, Rennes, France

6- Ecole des Hautes Etudes en Santé Publique (EHESP), Rennes, France

7- Service d'Oncologie Médicale, CHU Saint-André, Bordeaux, France

8- Service d'Anatomie et Cytologie Pathologiques, CHU Pellegrin, Bordeaux, France

9- Université de Rennes 1, Université Bretagne Loire, Service de Génétique Somatique des Cancers, F-35042 Rennes, France

10- Service d'Urologie, CHU Pellegrin, Bordeaux, France 


\section{Corresponding author:}

Solene-Florence Kammerer-Jacquet

Service d'Anatomie Pathologique

CHU Pontchaillou

2 rue Henri Le Guilloux

35033 Rennes cedex 9

Telephone number: 0033299284279

Fax number: 0033299284284 


\section{ABSTRACT}

Introduction. The selection of patients with metastatic clear-cell renal cell carcinoma (ccRCC) who may benefit from targeted tyrosine kinase inhibitors has been a challenge, even more so now with the advent of new therapies. Hilar fat infiltration (HFI) is a validated prognostic factor in non-metastatic ccRCC (TNM 2009 staging system) but has never been studied in metastatic patients. We aimed to assess its phenotype and prognostic impact in patients with metastatic ccRCC treated with first-line sunitinib.

Materials and methods: In a multicentric study, we retrospectively included 90 patients and studied the corresponding ccRCC at the pathological, immunohistochemical and molecular levels. Patient and tumour characteristics were compared using univariate and multivariate analysis. All the features were then studied by Cox models for prognostic impact.

Results: HFI was found in 42 patients (46.7\%), who had worse prognosis (Heng criteria) $(\mathrm{p}=0.003)$, liver metastases $(\mathrm{p}=0.036)$ and progressive diseases at first radiological evaluation $(\mathrm{p}=0.024)$. The corresponding ccRCC were associated with poor pathological prognostic factors that are well known in non-metastatic ccRCC. For these patients, median progressionfree survival (PFS) was 4 months versus 13 months $(\mathrm{p}=0.02)$, and median overall survival (OS) was 14 months versus 29 months $(\mathrm{p}=0.006$ ). In a multivariate Cox model integrating all the variables, only poor prognosis according to the Heng criteria and HFI remained independently associated with both PFS and OS.

Conclusion: HFI was demonstrated for the first time to be an independent poor prognostic factor. Its potential role in predicting resistance to anti-angiogenic therapy warrants further investigation.

Key-words: clear-cell renal cell carcinoma, sunitinib, prognostic, hilar fat infiltration 


\section{INTRODUCTION}

Renal cell carcinoma (RCC) accounts for 3\% of all adult cancers, with approximately 270000 new cases and 110000 deaths per year worldwide [1]. Clear cell renal cell carcinoma (ccRCC) is the most frequent histological subtype of renal cancer, estimated to account for approximately $70 \%$, with a poor prognosis [2]. Indeed, $20 \%$ of patients are metastatic at the time of diagnosis, and $30 \%$ will develop metastases. The 5-year overall survival is estimated to be $40 \%$ [1].

A better understanding of the oncogenic pathways involved in the oncogenesis of ccRCC, such as VHL/HIF/VEGF and PI3K/AKT/mTOR, led to the development of targeted therapies for metastatic patients. Sunitinib is an anti-angiogenic tyrosine kinase inhibitor (TKI) approved for use as a first-line treatment of metastatic ccRCC that is currently the most frequently administered [3, 4]. However, approximately $20 \%$ of patients are inherently resistant to this therapy because they progress according to response evaluation criteria in solid tumours (RECIST) at first evaluation [5].

A new approach is based on targeted immunotherapy using checkpoint inhibitors (antiPD-1, antiPD-L1 or anti-CTLA4 antibodies) since ccRCC is considered an immunogenic tumour [6]. Recently, nivolumab, an anti-PD1 antibody, has demonstrated efficiency as a second-line treatment versus everolimus (mTOR inhibitor) [7]. Most notably, a phase 3 study comparing anti-PD1 and anti-CTLA4 antibody association versus sunitinib in first-line treatment is ongoing, highlighting questions about chronologic treatment strategies. Oncologists currently face the challenge of drug selection to treat their patients but lack reliable predictors of response or prognostic factors that may help choose the most appropriate therapy.

Hilar fat infiltration, also known as renal sinus fat infiltration, was previously described in several studies as a poor prognostic factor in non-metastatic ccRCC [8]. Consequently, it was integrated in the TNM (Tumour Node Metastasis) staging system 2009, classifying tumours at least T3a [9]. This stage also includes peri-renal fat and venal invasion. Nevertheless, the impact of hilar fat infiltration has not been individually studied in metastatic ccRCC (mccRCC) thus far. 
In a retrospective cohort of metastatic patients with ccRCC treated by first-line sunitinib therapy, we aimed to correlate hilar fat infiltration with clinicopathological and molecular characteristics as well as clinical outcomes.

\section{PATIENTS AND METHODS}

\section{$\underline{\text { Patient selection and classification }}$}

The study population included metastatic patients who were at least 18 years old with histologically proven ccRCC. Primary ccRCC-specimens were collected from patients undergoing nephrectomy in two French University Hospitals (Rennes and Bordeaux, from UroCCR data base). Patients with metastatic ccRCC received sunitinib $(50 \mathrm{mg} /$ day, four weeks on/two weeks off) as first-line treatment (prior cytokine therapy was allowed) and completed at least one 28-day cycle of sunitinib. Tumour evaluation was realised according to Response Evaluation Criteria In Solid Tumours (RECIST 1.1) [10]. Follow-up chest/abdomen CT-scans were performed every 2 cycles of treatment ( 3 months). For each patient, the following clinical and pathologic information was gathered: age, sex, pTNM stage, tumour size, and nucleolar ISUP grade. Hilar fat infiltration was suspected during gross examination and was confirmed by microscopy. Histopathologic assessment was performed by three experienced pathologists (SFKJ, MY and NRL). For each patient, formalin-fixed paraffinembedded (FFPE) ccRCC were available. Informed consent was obtained from each patient, and institutional review board approval was obtained for this study (CNIL authorization receipt $1812601 v 0)$.

\section{Immunohistochemical study}

Protein expression patterns were assessed by immunohistochemistry using the following antibodies: anti-VEGFA (monoclonal, clone sp28, dilution, Spring Bioscience, California, USA), anti-CAIX (polyclonal, ab15086, dilution 1:1500, Abcam, Cambridge, UK), anti-PD1 (anti-PD-1 antibody, clone NAT105, dilution 1:50; Abcam, Cambridge, UK) and anti-PDL1 (anti-PD-L1 antibody, clone 130021, dilution 1:200; R\&D Systems, Minneapolis, USA) [1113]. The reactivity of antibodies was revealed with HRP-labelled polymer-conjugated secondary antibodies using diaminobenzidine (DAB) as the chromogen (Sigma-Aldrich, France). Negative controls were performed by omitting the primary antibody. The tumour expression for each antibody was independently evaluated (SFKJ and NRL) without 
knowledge of the case. The cut-off for positive cases was $30 \%$ of tumour cells for VEGF and $85 \%$ for CAIX as previously described [12, 14]. For PDL1, absent (0), weak (1), moderate (2) and strong expression (3) were reported and cases were then subdivided into negative (score 0-1) or positive (score 2-3) subgroups [15]. For PD1, immunostaining density was evaluated in tumour-infiltrating lymphocytes and was semi-quantified as absent, rare, moderate or dense as previously reported [15].

\section{$\underline{\text { VHL status }}$}

\section{Next-generation sequencing (NGS)}

For the VHL gene, the entire coding sequence and exon-intron junctions of exons 1, 2 and 3 were analysed. Genomic DNA was extracted using Magtration System 12GC (Bionobis) according to the manufacturer's instructions. Genomic DNA from all samples was quantitated with the Quan-iT PicoGreen dsDNA assay kit (Thermo Fisher Scientific). DNA target preparation and enrichment were performed by amplification using the Access Array® system (Fluidigm, San Francisco, USA). A 10-nucleotide "barcode" tag, specific to each sample and Illumina-specific sequencing adaptors were attached using secondary PCR. Purified products were then pooled and sequenced on an Illumina MiSeq NGS instrument (Illumina Inc., San Diego, California).

\section{Multiplex Ligation-dependent Probe Amplification (MLPA)}

Methylation-specific-MLPA (MS-MLPA) was used to detect CpG methylation islands in the VHL gene promotor. The SALSA MS-MLPA kit ME001B Tumour suppressor-1 allows detection of aberrant methylation of CpG-Islands located in the promoter region of the $V H L$ gene [16]. The unmethylated DNA does not generate a signal, and a normal probe signal is detected if the site is methylated.

\section{$\underline{\text { Statistical analysis }}$}

The focus of the study was to evaluate the relationship between HFI and clinicopathologic characteristics, molecular characteristics, and clinical outcomes. Associations were analysed with univariate analysis ( $\chi^{2}$, Fisher's and Mann-Whitney tests) and multivariate analysis (logistic regression). The second focus was to assess its clinical relevance by calculating 
progression-free survival (PFS) from the date of sunitinib introduction to the date of progression and overall survival (OS) from the date of sunitinib introduction to the date of death. PFS and OS were represented by Kaplan-Meier curves and compared by log-rank test. The prognostic impact of all the variables was then evaluated using univariate Cox regression models in PFS and OS. Therefore, we used a backward stepwise selection with the likelihood ratio criterion (inclusion/exclusion criteria: $\mathrm{p}<0.05$ ) for a multivariate Cox regression model. All statistical tests were two sided and performed at a significance level of 0.05 using StataCorp version 14 and $\mathrm{R}$ version 3.3.0.

\section{RESULTS}

\section{$\underline{\text { Patient and tumour characteristics }}$}

Patient and tumour characteristics are presented in Table 1. The study retrospectively included 90 metastatic patients with primary ccRCC who underwent nephrectomy from 1997 to 2013. Men were more represented (62.2\% versus 37.8\%). According to the Heng criteria, most of patients were in the intermediate group (47.7\%). Locally advanced tumours were most represented (stage T3-T4 in 75.5\% of patients) and showed a high nucleolar ISUP grade 3 or $4(\mathrm{n}=88,92.3 \%)$. Forty-two patients $(46.7 \%)$ had ccRCC with hilar fat infiltration. Metastases were present at initial diagnostic for $55.6 \%$ of patients. With time, non-metastatic patients at diagnosis developed metastases on average 10.5 months (0-144 months) with a median follow-up was 43 months (1-171 months) from nephrectomy. More than two-thirds of all patients presented multiple metastatic sites $(n=69 ; 76.7 \%)$. The most common metastatic sites were the lung $(75.6 \%)$, bone $(53.3 \%)$ and liver $(23.3 \%)$. Eighty-five patients $(94.4 \%)$ experienced progression and $71(78.9 \%)$ died from their cancer. The mean follow-up period was 25 months (range 1-76 months) from sunitinib introduction.

Correlation between the clinical, pathological, immunohistochemical and molecular phenotype of tumours and hilar fat infiltration

Hilar fat infiltration was associated with poor prognosis according to both the Heng and MSKCC criteria ( $\mathrm{p}=0.003$ and 0.006 , respectively) and was also associated with liver metastasis $(\mathrm{p}=0.036)$, Table 2 . Hilar fat infiltration was also associated with early resistance to 
sunitinib treatment, defined as disease progression at the first radiologic evaluation $(\mathrm{p}=0.024)$. Among pathological characteristics, hilar fat infiltration was associated with the sarcomatoid component $(\mathrm{p}=0.008)$, microvascular invasion $(\mathrm{p}=0.013)$ and tumour necrosis $(\mathrm{p}=0.012)$. Perirenal fat infiltration $(\mathrm{p}=0.035)$ and local node metastasis $(\mathrm{p}=0.005)$ were also significantly associated with hilar fat infiltration. No association with CAIX, VEGFA, PD1 and PDL1 expression by immunohistochemistry were identified. Fewer VHL gene mutations were found in $\mathrm{ccRCC}$ with hilar fat infiltration $(\mathrm{p}=0.023)$. After logistic regression, three factors remained significantly associated with hilar fat infiltration: peri-renal fat infiltration $(\mathrm{p}=0.037)$, poor prognosis $($ Heng score $)(\mathrm{p}=0.002)$ and local node metastasis $(\mathrm{p}=0.006)$.

\section{Correlation between hilar fat infiltration and survival}

Kaplan-Meier curves for PFS and OS are presented in Figures 1 and 2, respectively. Metastatic patients with hilar fat infiltration had a median PFS of 4 months versus 13 months for patients without hilar fat infiltration $(\mathrm{p}=0.020)$. Similarly, patients with hilar fat infiltration had a significantly shorter survival, with a median OS of 14 months versus 29 months for patients without hilar fat infiltration $(\mathrm{p}=0.006)$.

\section{Correlation between clinicopathological features and survival outcome}

In univariate Cox model, clinicopathological factors associated with worse PFS were age $\geq 65$ years $(\mathrm{p}=0.044)$, poor prognosis according to the Heng and MSKCC criteria $(\mathrm{p}=0.001$ and $\mathrm{p}=0.004$, respectively), liver metastasis $(\mathrm{p}=0.004)$, and hilar fat infiltration $(\mathrm{p}=0.027)$, Table 3 . A multivariate Cox model showed that age $\geq 65$ years, poor prognosis according to the Heng criteria and hilar fat infiltration remained significantly associated with poor PFS.

In univariate Cox model, OS was associated with poor prognosis according to the Heng and $\operatorname{MSKCC}$ criteria $(\mathrm{p}=0.001)$, liver metastasis $(\mathrm{p}=0.017)$ and hilar fat infiltration $(\mathrm{p}=0.007)$, Table 4. In a multivariate Cox model, poor prognosis according to the Heng criteria and hilar fat infiltration were the only two factors that remained significantly associated with poor OS.

\section{DISCUSSION}


To our knowledge, this is the first study to assess the phenotype of ccRCC with hilar fat infiltration in metastatic patients who were treated by first-line sunitinib and to evaluate its prognostic value. Hilar fat infiltration was associated with aggressive tumours with worse outcomes.

Hilar fat infiltration was associated with poor prognostic factors already identified in nonmetastatic ccRCC, such as nucleolar ISUP grade 4, sarcomatoid component, tumour necrosis, microvascular invasion, higher tumour stage and local node extension [17]. Among pathological factors, local node extension and peri-renal fat infiltration remained independently associated with hilar fat infiltration in metastatic patients. Hilar fat area is characterised by dense lymphatic vessels favouring metastatic spread through lymph nodes. Moreover, ccRCC with hilar fat infiltration are larger and have a more frequent peri-renal extent, as we observed in our series. Finally, they were associated with fewer $V H L$ mutations, previously associated with poor prognosis factors [18]. The phenotype of these ccRCC may be completed by further molecular studies to understand the biological mechanisms underlying these results.

In the literature, predictors of response and prognostic factors for patients with metastatic renal cell carcinoma treated with anti-VEGF therapies have been extensively studied [19, 20]. However, these studies are often retrospective with a relative limited number of patients. In addition, the histology data include not only ccRCC but also papillary and chromophobe renal cell carcinoma, although their carcinogenesis is different [21]. Finally, anti-VEGF therapies comprise sunitinib and other TKI, whose targets are different. Although our study shared retrospective and size limits impacting multivariate analysis, we included 90 metastatic patients with sunitinib first-line therapy and histologically proven ccRCC.

Few predictive and prognostic markers are described in the literature in metastatic ccRCC with first-line sunitinib. Single-nucleotide polymorphisms and transcriptomic clusters have shown interesting results but were not investigated in this study [22, 23]. Moreover, consistent with our results, up to now, no immunohistochemical markers were associated with both PFS and OS. In accordance with other studies, we confirmed the prognostic impact of the Heng score [24]. 
Hilar fat is continuous with visceral fat infiltration. The latter characteristic was previously described as an independent prognostic factor in metastatic ccRCC treated by anti-angiogenic therapies[25]. Adipose tissue may be involved through the production of adipokines, such as IL-6 and TNF $\alpha$, leading to cancer growth and dysregulated angiogenesis [26]. Indeed, insulinlike growth factors produced by adipocytes and the release of inflammatory cytokines by infiltrating lymphocytes have cancer-promoting and angiogenic effects, by stimulating VEGF production [27]. This particular microenvironment may promote the emergence of aggressive clones favouring tumour dissemination and treatment resistance.

We have demonstrated, for the first time in metastatic ccRCC, a significant association between hilar fat infiltration and disease progression in RECIST at first evaluation even if association did not remain significant after logistic regression. If validated on an external cohort, it may constitute a potential candidate for predictor of early resistance to sunitinib therapy. Otherwise, hilar fat infiltration along with the Heng criteria were the only two variables independently associated with both poor PFS and OS although the multivariate Cox model was limited by the size of our cohort. Liver metastases were associated with worse PFS and OS but did not remain significant after multivariate analysis. Age over 65 years was also noteworthy but was limited to PFS. Among all the pathological variables we studied, hilar fat infiltration was the only one to have a poor prognostic impact. It is not known if the worse survival outcomes in patients with HFI is due to sunitinib resistance, especially since RECIST progression was not significant on multivariate analysis, however; it would be interesting to further investigate.

In the TNM staging system, T3a stage combines tumours with hilar, peri-renal fat infiltration or renal vein invasion without discriminating them [9]. Our study demonstrated the particularly worse prognosis of ccRCC with hilar fat infiltration in metastatic patients. Indeed, peri-renal fat and renal vein invasion were not associated with PFS and OS. These results suggest that, in future studies, it would be worthwhile to individualise and report hilar fat infiltration.

To conclude, our study demonstrated hilar fat infiltration as a new independent prognostic factor in metastatic patients with ccRCC treated by first-line sunitinib therapy. This result, if confirmed in larger and prospective studies, could have a substantial impact in predicting 
prognosis under sunitinib therapy, which has become an even more crucial issue with the advent of targeted immunotherapies.

\section{ACKNOWLEDGMENTS}

The authors would like to thank the Ligue Contre le Cancer, CORECT, Rennes Hospital and the French Institute of Cancer (INCa) for their financial support.

The authors would also like to thank the Rennes Hospital Biological Resources Center (BB0033-00056, http://www.crbsante-rennes.com/) for patient sample management as well as Pascale Bellaud and Roselyne Viel from the Histopathology platform H2P2-BIOSIT at the Faculty of Medicine in Rennes for their technical support.

\section{CONFLICT OF INTEREST}

Authors indicated no conflict of interest in relation to this study

\section{REFERENCES}

[1] Ljungberg B, Campbell SC, Choi HY, Jacqmin D, Lee JE, Weikert S, et al. The epidemiology of renal cell carcinoma. Eur Urol. 2011;60:615-21.

[2] Srigley JR, Delahunt B, Eble JN, Egevad L, Epstein JI, Grignon D, et al. The International Society of Urological Pathology (ISUP) Vancouver Classification of Renal Neoplasia. The American journal of surgical pathology. 2013;37:1469-89.

[3] Motzer RJ, Hutson TE, Tomczak P, Michaelson MD, Bukowski RM, Rixe O, et al. Sunitinib versus interferon alfa in metastatic renal-cell carcinoma. N Engl $\mathrm{J}$ Med. 2007;356:115-24.

[4] Miller LA, Stemkowski S, Saverno K, Lane DC, Tao Z, Hackshaw MD, et al. Patterns of Care in Patients with Metastatic Renal Cell Carcinoma Among a U.S. Payer Population with Commercial or Medicare Advantage Membership. J Manag Care Spec Pharm. 2016;22:21926.

[5] Abdullah SE, Perez-Soler R. Mechanisms of resistance to vascular endothelial growth factor blockade. Cancer. 2012;118:3455-67.

[6] Thompson RH, Dong H, Kwon ED. Implications of B7-H1 expression in clear cell carcinoma of the kidney for prognostication and therapy. Clin Cancer Res. 2007;13:709s-15s.

[7] Motzer RJ, Escudier B, McDermott DF, George S, Hammers HJ, Srinivas S, et al. Nivolumab versus Everolimus in Advanced Renal-Cell Carcinoma. N Engl J Med. 2015;373:1803-13.

[8] Baccos A, Brunocilla E, Schiavina R, Borghesi M, Rocca GC, Chessa F, et al. Differing risk of cancer death among patients with pathologic T3a renal cell carcinoma: identification 
of risk categories according to fat infiltration and renal vein thrombosis. Clinical genitourinary cancer. 2013;11:451-7.

[9] Martinez-Salamanca JI, Huang WC, Millan I, Bertini R, Bianco FJ, Carballido JA, et al. Prognostic impact of the 2009 UICC/AJCC TNM staging system for renal cell carcinoma with venous extension. Eur Urol. 2011;59:120-7.

[10] Eisenhauer EA, Therasse P, Bogaerts J, Schwartz LH, Sargent D, Ford R, et al. New response evaluation criteria in solid tumours: revised RECIST guideline (version 1.1). Eur J Cancer. 2009;45:228-47.

[11] Kammerer-Jacquet SF, Crouzet L, Brunot A, Dagher J, Pladys A, Edeline J, et al. Independent association of PD-L1 expression with noninactivated VHL clear cell renal cell carcinoma-A finding with therapeutic potential. International journal of cancer Journal international du cancer. 2016.

[12] Bui MH, Seligson D, Han KR, Pantuck AJ, Dorey FJ, Huang Y, et al. Carbonic anhydrase IX is an independent predictor of survival in advanced renal clear cell carcinoma: implications for prognosis and therapy. Clin Cancer Res. 2003;9:802-11.

[13] Rioux-Leclercq N, Fergelot P, Zerrouki S, Leray E, Jouan F, Bellaud P, et al. Plasma level and tissue expression of vascular endothelial growth factor in renal cell carcinoma: a prospective study of 50 cases. Human pathology. 2007;38:1489-95.

[14] Rioux-Leclercq N, Karakiewicz PI, Trinh QD, Ficarra V, Cindolo L, de la Taille A, et al. Prognostic ability of simplified nuclear grading of renal cell carcinoma. Cancer. 2007;109:868-74.

[15] Shin SJ, Jeon YK, Kim PJ, Cho YM, Koh J, Chung DH, et al. Clinicopathologic Analysis of PD-L1 and PD-L2 Expression in Renal Cell Carcinoma: Association with Oncogenic Proteins Status. Ann Surg Oncol. 2015.

[16] Jeuken JW, Cornelissen SJ, Vriezen M, Dekkers MM, Errami A, Sijben A, et al. MSMLPA: an attractive alternative laboratory assay for robust, reliable, and semiquantitative detection of MGMT promoter hypermethylation in gliomas. Lab Invest. 2007;87:1055-65.

[17] Letang N, Cabaniols L, Pouessel D, Robert M, Iborra F, Culine S, et al. [Prognostic factors in renal cell carcinoma]. Bull Cancer. 2009;96:475-84.

[18] Yao M, Yoshida M, Kishida T, Nakaigawa N, Baba M, Kobayashi K, et al. VHL tumor suppressor gene alterations associated with good prognosis in sporadic clear-cell renal carcinoma. J Natl Cancer Inst. 2002;94:1569-75.

[19] Vano YA, Tartour E, Fournier LS, Beuselinck B, Mejean A, Oudard S. Prognostic factors in patients with advanced renal cell carcinoma treated with VEGF-targeted agents. Expert Rev Anticancer Ther. 2014;14:523-42.

[20] Motzer RJ, Escudier B, Bukowski R, Rini BI, Hutson TE, Barrios CH, et al. Prognostic factors for survival in 1059 patients treated with sunitinib for metastatic renal cell carcinoma. Br J Cancer. 2013;108:2470-7.

[21] Banumathy G, Cairns P. Signaling pathways in renal cell carcinoma. Cancer Biol Ther. 2010;10:658-64.

[22] Beuselinck B, Job S, Becht E, Karadimou A, Verkarre V, Couchy G, et al. Molecular Subtypes of Clear Cell Renal Cell Carcinoma Are Associated with Sunitinib Response in the Metastatic Setting. Clin Cancer Res. 2015.

[23] Beuselinck B, Karadimou A, Lambrechts D, Claes B, Wolter P, Couchy G, et al. Singlenucleotide polymorphisms associated with outcome in metastatic renal cell carcinoma treated with sunitinib. Br J Cancer. 2013;108:887-900.

[24] Heng DY, Xie W, Regan MM, Warren MA, Golshayan AR, Sahi C, et al. Prognostic factors for overall survival in patients with metastatic renal cell carcinoma treated with vascular endothelial growth factor-targeted agents: results from a large, multicenter study. J Clin Oncol. 2009;27:5794-9. 
[25] Ladoire S, Bonnetain F, Gauthier M, Zanetta S, Petit JM, Guiu S, et al. Visceral fat area as a new independent predictive factor of survival in patients with metastatic renal cell carcinoma treated with antiangiogenic agents. The oncologist. 2011;16:71-81.

[26] Nieman KM, Romero IL, Van Houten B, Lengyel E. Adipose tissue and adipocytes support tumorigenesis and metastasis. Biochimica et biophysica acta. 2013;1831:1533-41.

[27] Cao Y. Angiogenesis modulates adipogenesis and obesity. The Journal of clinical investigation. 2007;117:2362-8. 
Figure 1: Kaplan Meier curve representing progression-free survival according to hilar fat infiltration.

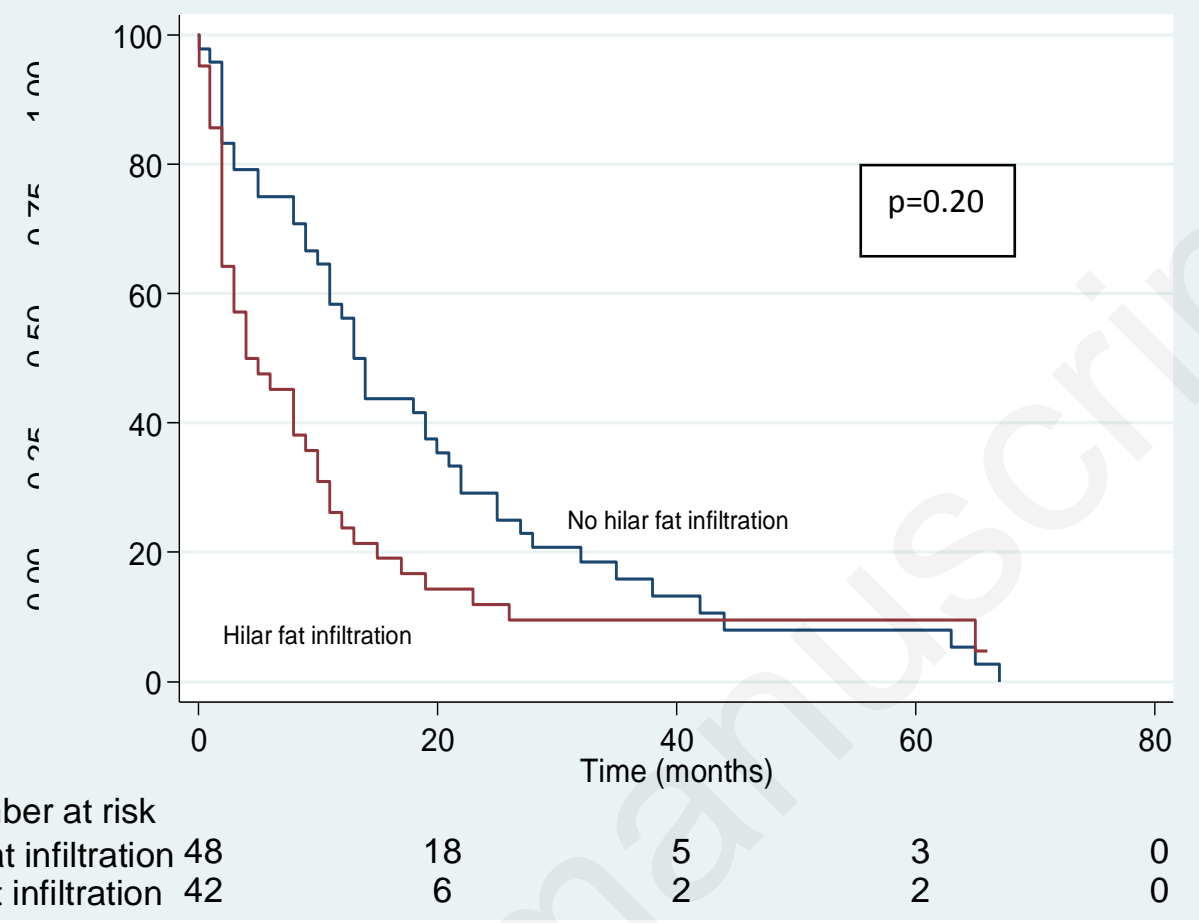

Figure 2: Kaplan Meier curve representing overall survival according to hilar fat infiltration.

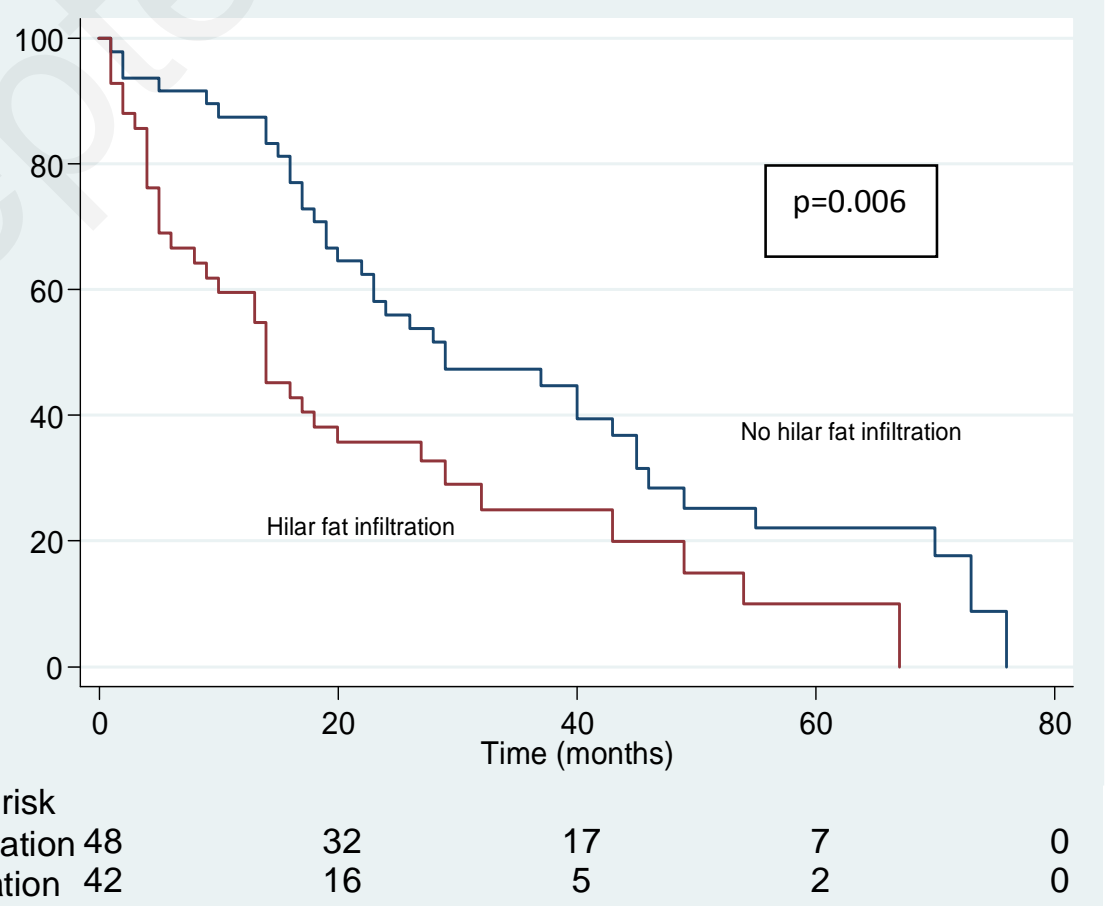


Table 1: Patient and tumour characteristics of 90 metastatic clear cell renal cell carcinoma

\begin{tabular}{|c|c|c|}
\hline Characteristics & \multicolumn{2}{|c|}{ Number } \\
\hline Age (years) & \multirow{2}{*}{\multicolumn{2}{|c|}{61.3}} \\
\hline Mean & & \\
\hline Range & \multicolumn{2}{|c|}{$37-85$} \\
\hline \multicolumn{3}{|l|}{ Sexe } \\
\hline Male & 56 & $62.2 \%$ \\
\hline Female & 34 & $37.8 \%$ \\
\hline \multicolumn{3}{|l|}{ Heng score } \\
\hline Favourable & 20 & $22.2 \%$ \\
\hline Intermediate & 43 & $47.8 \%$ \\
\hline Poor & 27 & $30.0 \%$ \\
\hline \multicolumn{3}{|l|}{ T stage } \\
\hline $\mathrm{T} 1$ & 14 & $15.6 \%$ \\
\hline $\mathrm{T} 2$ & 8 & $8.9 \%$ \\
\hline $\mathrm{T} 3$ & 63 & $70.0 \%$ \\
\hline $\mathrm{T} 4$ & 5 & $5.6 \%$ \\
\hline \multicolumn{3}{|l|}{ N stage } \\
\hline N0 & 75 & $83.3 \%$ \\
\hline $\mathrm{N} 1$ & 15 & $16.7 \%$ \\
\hline \multicolumn{3}{|l|}{ M stage } \\
\hline M0 & 40 & $44.4 \%$ \\
\hline M1 & 50 & $55.6 \%$ \\
\hline \multicolumn{3}{|l|}{ Time to develop metastasis (months) } \\
\hline Mean & \multicolumn{2}{|c|}{10.5} \\
\hline Range & \multicolumn{2}{|c|}{$0-144$} \\
\hline \multicolumn{3}{|l|}{ Metastatic localisations } \\
\hline Lung & 68 & $75.6 \%$ \\
\hline Bone & 48 & $53.3 \%$ \\
\hline Liver & 21 & $23.3 \%$ \\
\hline Cerebral & 19 & $21.1 \%$ \\
\hline Multiple localisations & 69 & $76.7 \%$ \\
\hline \multicolumn{3}{|l|}{ Tumor size (cm) } \\
\hline Mean & \multicolumn{2}{|c|}{9.6} \\
\hline Range & \multicolumn{2}{|c|}{$2-9.5$} \\
\hline \multicolumn{3}{|l|}{ Nucleolar ISUP grade } \\
\hline Grade 2 & 7 & $7.8 \%$ \\
\hline
\end{tabular}




\begin{tabular}{|ll|cc|} 
& Grade 3 & 33 & $36.7 \%$ \\
& Grade 4 & 50 & $55.6 \%$ \\
\hline RECIST 1 & & 1 & \\
& Complete response & 27 & $30.0 \%$ \\
& Partial response & 34 & $37.8 \%$ \\
& Stable disease & 28 & $31.1 \%$ \\
\hline
\end{tabular}

Abbreviations: TNM: Tumor Node Metastasis, RECIST 1: first evaluation according to response evaluation criteria in solid tumours (RECIST) 1.1 criteria, ISUP: International Society of Uropathology 
Table 2: Clinicopathological, radiological and molecular comparisons between metastatic clear cell renal cell carcinoma according to hilar fat infiltration.

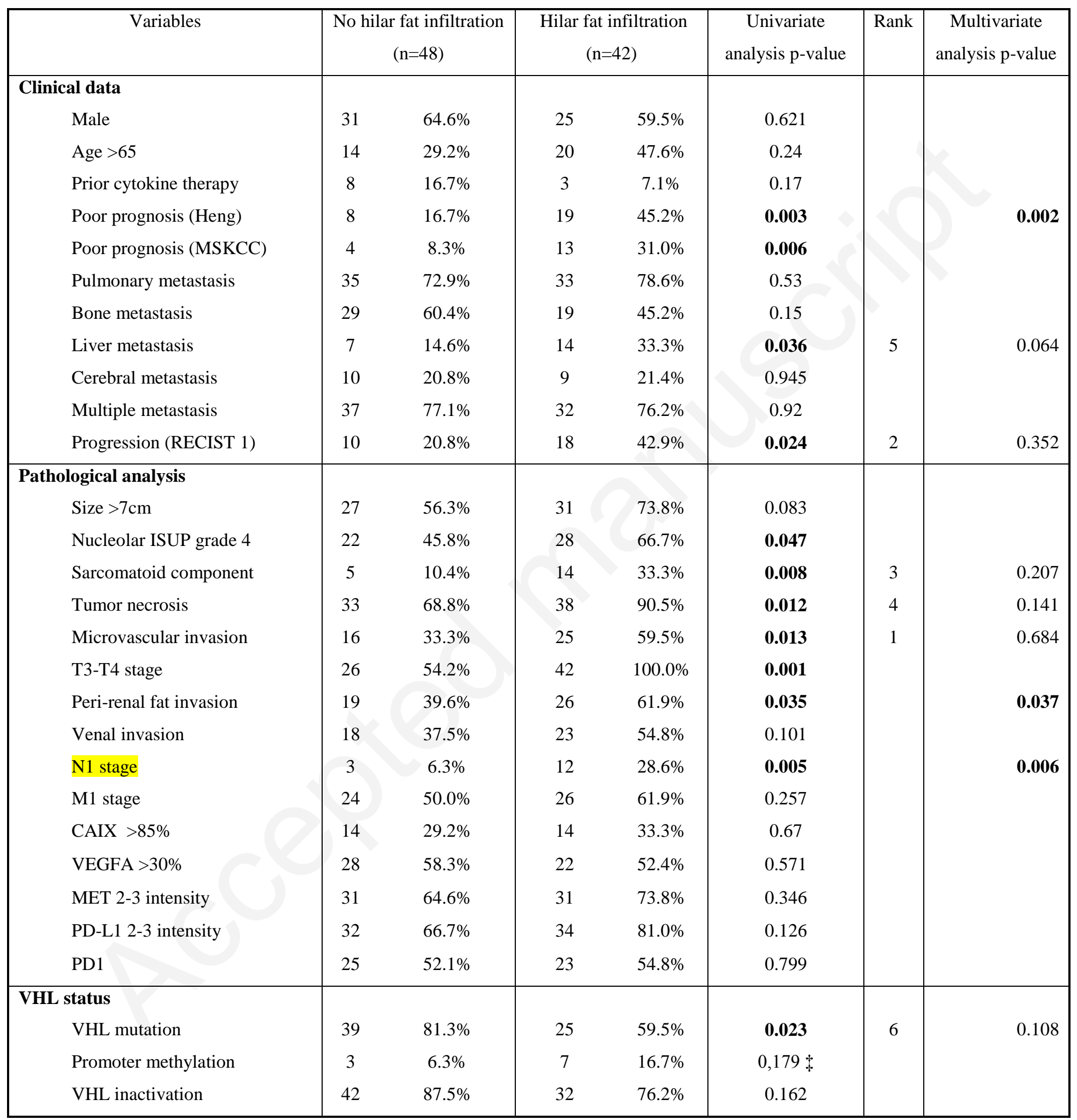


Table 3: Cox model for progression-free survival

\begin{tabular}{|c|c|c|c|c|c|c|c|}
\hline \multirow[b]{2}{*}{ Variables } & \multicolumn{3}{|c|}{ Univariate Cox PH Model } & \multicolumn{4}{|c|}{ Multivariate Cox PH Model } \\
\hline & HR & $95 \% \mathrm{CI}$ & $P$ & Rank & HR & $95 \%$ CI & $P$ \\
\hline \multicolumn{8}{|l|}{ Clinical data } \\
\hline Male & 0.74 & $0.47-1.15$ & 0.176 & \multirow{9}{*}{1} & \multirow{3}{*}{1.663} & \multirow{3}{*}{$1.06-0.58$} & \multirow{3}{*}{0.024} \\
\hline Age $>65$ & 1.56 & $1.01-2.41$ & 0.044 & & & & \\
\hline Prior cytokine therapy & 1.01 & $0.53-1.91$ & 0.981 & & & & \\
\hline Poor prognosis (Heng) & 2.59 & $1.59-4.24$ & 0.001 & & \multirow[t]{2}{*}{2.501} & $1.51-4.12$ & \multirow[t]{2}{*}{0.001} \\
\hline Poor prognosis (MSKCC) & 2.26 & $1.30-3.93$ & 0.004 & & & & \\
\hline Liver metastasis & 1.72 & $1.04-2.85$ & 0.035 & & \multirow[t]{4}{*}{1.300} & $0.78-2.18$ & \multirow[t]{4}{*}{0.316} \\
\hline Bone metastasis & 1.16 & $0.75-1.80$ & 0.49 & & & & \\
\hline Cerebral metastasis & 1.50 & $0.89-2.52$ & 0.123 & & & & \\
\hline Multiple metastasis & 1.17 & $0.70-.96$ & 0.549 & & & & \\
\hline \multicolumn{8}{|l|}{ Pathological analysis } \\
\hline Size $>7 \mathrm{~cm}$ & 1.11 & $0.71-1.73$ & 0.641 & & \multirow{16}{*}{1.580} & \multirow{16}{*}{ 1.01-2.47 } & \multirow{16}{*}{0.045} \\
\hline Nucleolar ISUP grade 4 & 1.25 & $0.81-1,93$ & 0.305 & & & & \\
\hline Sarcomatoid component & 1.31 & $0.76-2.25$ & 0.33 & & & & \\
\hline Tumor necrosis & 1.53 & $0.89-2.62$ & 0.121 & & & & \\
\hline Microvascular invasion & 1.12 & $0.73-1.73$ & 0.599 & & & & \\
\hline T3-T4 stage & 1.29 & $0.79-2,12$ & 0.307 & & & & \\
\hline Hilar invasion & 1.63 & $1.06-2.53$ & 0.027 & & & & \\
\hline Peri-renal fat invasion & 1.05 & $0.68-1.61$ & 0.821 & & & & \\
\hline Venal invasion & 0.87 & $0.56-1.35$ & 0.54 & & & & \\
\hline N1 stage & 1.45 & $0.81-2.60$ & 0.21 & & & & \\
\hline M1 stage & 1.12 & $0.73-1.73$ & 0.595 & & & & \\
\hline CAIX $>85 \%$ & 0.86 & $0.54-1.37$ & 0.539 & & & & \\
\hline VEGFA $>30 \%$ & 1.37 & $0.88-2.12$ & 0.161 & & & & \\
\hline MET 2-3 intensity & 1.05 & $0.66-1.67$ & 0.835 & & & & \\
\hline PD1 & 1.07 & $0.70-1.65$ & 0.749 & & & & \\
\hline PD-L1 2-3 intensity & 1.29 & $0.80-2.09$ & 0.29 & & & & \\
\hline \multicolumn{8}{|l|}{ VHL status } \\
\hline VHL mutation & 1.01 & $0.63-1.63$ & 0.957 & & & & \\
\hline Promoter methylation & 1.05 & $0.53-2.11$ & 0.88 & & & & \\
\hline VHL inactivation & 1.05 & $0.60-1.85$ & 0.857 & & & & \\
\hline
\end{tabular}


Table 4: Cox model for overall survival

\begin{tabular}{|c|c|c|c|c|c|c|c|}
\hline \multirow[b]{2}{*}{ Variables } & \multicolumn{3}{|c|}{ Univariate Cox PH Model } & \multicolumn{4}{|c|}{ Multivariate Cox PH Model } \\
\hline & HR & $95 \% \mathrm{CI}$ & $P$ & Rank & HR & $95 \%$ CI & $P$ \\
\hline \multicolumn{8}{|l|}{ Clinical data } \\
\hline Male & 0.74 & $0.45-1.19$ & 0.22 & \multirow{9}{*}{1} & \multirow{5}{*}{3.646} & & \multirow{5}{*}{0.001} \\
\hline Age $>65$ & 1.42 & $0.88-2.29$ & 0.143 & & & & \\
\hline Prior cytokine therapy & 1.40 & $0.74-2.68$ & 0.301 & & & & \\
\hline Poor prognosis (Heng) & 3.93 & $2.34-6.61$ & 0.001 & & & $2.15-6.18$ & \\
\hline Poor prognosis (MSKCC) & 3.41 & $1.92-6.05$ & 0.001 & & & & \\
\hline Liver metastasis & 1.91 & $1.12-3.25$ & 0.017 & & \multirow[t]{4}{*}{1.512} & $0.88-2.59$ & \multirow[t]{4}{*}{0.133} \\
\hline Bone metastasis & 1.32 & $0.82-2.13$ & 0.255 & & & & \\
\hline Cerebral metastasis & 1.09 & $0.61-1.95$ & 0.757 & & & & \\
\hline Multiple metastasis & 1.11 & $0.63-1.95$ & 0.708 & & & & \\
\hline \multicolumn{8}{|l|}{ Pathological analysis } \\
\hline Size $>7 \mathrm{~cm}$ & 1.23 & $0.75-2.01$ & 0.412 & & \multirow{16}{*}{1.666} & \multirow{16}{*}{$1.017-2.728$} & \multirow{16}{*}{0.042} \\
\hline Nucleolar ISUP grade 4 & 1.37 & $0.84-2.21$ & 0.204 & & & & \\
\hline Sarcomatoid component & 1.31 & $0.72-2.38$ & 0.368 & & & & \\
\hline Tumor necrosis & 1.67 & $0.89-3.10$ & 0.109 & & & & \\
\hline Microvascular invasion & 1.44 & $0.90-2.31$ & 0.127 & & & & \\
\hline T3-T4 stage & 1.55 & $0.88-2.75$ & 0.132 & & & & \\
\hline Hilar invasion & 1.93 & $1.19-3.13$ & 0.007 & & & & \\
\hline Peri-renal fat invasion & 1.12 & $0.70-1.80$ & 0.634 & & & & \\
\hline Venal invasion & 1.06 & $0.66-1.70$ & 0.792 & & & & \\
\hline N1 stage & 1.48 & $0.82-2.66$ & 0.192 & & & & \\
\hline M1 stage & 1.42 & $0.87-2.30$ & 0.162 & & & & \\
\hline CAIX $>85 \%$ & 0.75 & $0.45-1.27$ & 0.288 & & & & \\
\hline VEGFA $>30 \%$ & 1.04 & $0.65-1.66$ & 0.879 & & & & \\
\hline MET 2-3 intensity & 0.96 & $0.58-1.57$ & 0.862 & & & & \\
\hline PD1 & & & & & & & \\
\hline PD-L1 2-3 intensity & 1.00 & $0.99-1.00$ & 0.483 & & & & \\
\hline \multicolumn{8}{|l|}{ VHL status } \\
\hline VHL mutation & 0.88 & $0.52-1.47$ & 0.624 & & & & \\
\hline Promoter methylation & 1.27 & $0.60-2.66$ & 0.524 & & & & \\
\hline VHL inactivation & 0.97 & $0.53-1.78$ & 0.930 & & & & \\
\hline
\end{tabular}

